Western North American Naturalist 67(4), (C) 2007, pp. 524-537

\title{
THE SCOTOPIC VISUAL SENSITIVITY OF FOUR SPECIES OF TROUT: A COMPARATIVE STUDY
}

\author{
Russell B. Rader ${ }^{1,2}$, Timberley Belish ${ }^{1,3}$, Michael K. Young1,4, and John Rothlisberger 5
}

\begin{abstract}
We compared the maximum scotopic visual sensitivity of 4 species of trout from twilight (mesotopic) to fully dark-adapted vision. Scotopic vision is the minimum number of photons to which a fully dark-adapted animal will show a behavioral response. A comparison of visual sensitivity under controlled laboratory conditions showed that brown trout (Salmo trutta) and brook trout (Salvelinus fontinalis) had maximum scotopic thresholds $\left(1.1 \times 10^{-4} \mu \mathrm{mol} \cdot \mathrm{m}^{-2} \mathrm{~s}^{-1}\right.$, $\sim 0.005$ lux) 2 times lower than rainbow trout (Oncorhyncus mykiss) and Snake River cutthroat trout (Oncorhynchus clarki bouvieri), which did not differ from each other $\left(2.1 \times 10^{-4} \mu \mathrm{mol} \cdot \mathrm{m}^{-2} \mathrm{~s}^{-1}, \sim 0.01 \mathrm{lux}\right)$. A literature review tended to corroborate these results in that brown trout and brook trout were reported to be more active during the night and at twilight than cutthroat trout and rainbow trout. We also measured light intensity within open versus shaded reaches during the day, dusk, and night in 3 Rocky Mountain streams. The scotopic sensitivity of brown trout and brook trout was sufficient to allow foraging during all twilight periods and under average nighttime light intensities in open and shaded reaches, whereas the scotopic sensitivity of rainbow trout and cutthroat trout may restrict their foraging to relatively bright nocturnal conditions (twilight or a moonlit night). Native cutthroat trout restoration efforts may have greater success in open versus shaded stream reaches in the Rocky Mountains and elsewhere.
\end{abstract}

Key words: light sensitivity, scotopic vision, cutthroat restoration, salmonids.

Three attributes of light can affect trout vision: (1) intensity (photons $\cdot$ area $^{-1}$ time $^{-1}$ ), (2) spectral composition (wavelength [nm]), and (3) polarization (the major plane of vibration in which most photons oscillate). Recent research has demonstrated that representatives of the major extant clades of Salmoninae (i.e., rainbow trout, cutthroat trout, brook trout, brown trout, and Atlantic salmon) are able to detect polarized light (Coughlin and Hawryshyn 1995, NovalesFlamarique and Hawryshyn 1997, Parkyn and Hawryshyn 2000) and can see light of varying irradiance and spectral composition, including ultraviolet, blue, green, yellow, and red (e.g., Douglas 1982, Bowmaker and Kunz 1987, Hawryshyn et al. 1989, Deutschlander et al. 2001). Most of these studies have examined the mechanisms underlying trout vision at the cellular/physiological level using isolated tissues or induced immobilization of whole organisms (e.g., Hawryshyn and McFarland 1987, Hawryshyn et al. 1989), whereas far fewer studies have examined the behavioral effects of these physiological differences in trout vision. Douglas and Hawryshyn (1990) emphasized that electrophysiological studies, although valuable, were not reliable indicators of the response of the whole animal: "Only behavioural (psychophysical) studies can tell us what the animal's visual system is truly capable of achieving."

Photoreceptor cells (rods and cones) respond to the number of photons striking the retina. Scotopic vision is not possible until sufficient photons have struck the retina to excite a nervous impulse (e.g., Partridge 1990). Maximum sensitivity to dim light has been defined as the minimum number of photons to which a fully dark-adapted animal will show a behavioral response (Douglas and Hawryshyn 1990). Darkadapted scotopic vision is produced by a number of electrophysiological and biomechanical changes in the retina (e.g., Bowmaker 1990, Wagner 1990). Photopic vision occurs during the day, whereas mesotopic vision is intermediate between photopic and scotopic vision. Twilight periods span the transition from photopic to scotopic vision. We compared the maximum scotopic sensitivity of 4 species of trout from twilight (mesotopic) to fully darkadapted vision. Maximum scotopic sensitivity

\footnotetext{
${ }^{1}$ USDA Forest Service, Rocky Mountain Research Station, 222 South 22nd Street, Laramie, WY 82070

${ }_{2}^{2}$ Present address: Department of Integrative Biology, Brigham Young University, Provo, UT 84602-5181. E-mail: russell_rader@byu.edu

${ }_{3}^{3}$ Present address: Parsons Environmental Consulting, 1700 Broadway, Suite 900, Denver, CO 80290.

${ }^{4}$ Present address: Rocky Mountain Research Station, Forestry Sciences Laboratory, 800 East Beckwith, Box 8089, Missoula, MT 59807.

${ }^{5}$ University of Notre Dame, Department of Biological Sciences, Box 369, Notre Dame, IN 46556.
} 
in dark-adapted specimens of 4 species of trout was determined by the earliest commencement of visual behavior during a simulated dawn.

In the Rocky Mountains, introduced brook trout, brown trout, and rainbow trout (common names follow Nelson et al. 2004) have displaced native cutthroat trout, reducing their distribution to a small fraction of their historic range (e.g., Young et al. 1996). Introduced trout may grow faster and achieve a greater reproductive output than native cutthroat trout if they can feed longer because of a greater scotopic sensitivity. Thus, scotopic sensitivity may partially explain the ability of introduced trout to exclude native cutthroat trout.

We are aware of only 3 behavioral studies using whole organisms to compare the scotopic vision of different salmonid species. Henderson and Northcote (1985) found that lake populations of Dolly Varden (Salvelinus malma) foraging under dim light were better at detecting prey than cutthroat trout (Oncorhynchus clarki clarki). Similarly, Robinson and Tash (1979) found that brown trout (Salmo trutta) were more efficient at eating brine shrimp at lower light levels (starlight $>0.001$ lux) than Apache trout (Oncorhynchus gilae apache). These data indicate that at least 1 species of brook trout and brown trout have greater scotopic sensitivity than cutthroat trout. Confer et al. (1978) found that the reaction distance of lake trout (Salmo namaycush) and brook trout (Salmo fontinalis) to planktonic prey was similar at illuminances equal to 1.0 lux, suggesting that different species in the same genus may have similar scotopic sensitivity.

Thus, we hypothesized that the scotopic vision of brown trout and brook trout would be more sensitive than that of fine-spotted Snake River cutthroat trout (Oncorhynchus clarki bouvieri). However, we had no basis for predicting possible differences in the scotopic sensitivity among rainbow trout (Oncorhynchus mykiss), fine-spotted Snake River cutthroat trout, brown trout, and brook trout, because of the absence of previous research. Similarly, there are no studies documenting 24-hour fluctuations in light intensity in stream ecosystems (day, twilight, and night). Field measurements, combined with laboratory experiments to determine the scotopic sensitivity of these trout, allowed us to determine the percentage of time that light levels are greater than scotopic thresholds for each species. These percentages determine the maximum amount of time different species can forage in different reach types.

Our objectives were to (1) experimentally compare the scotopic visual sensitivity of brook trout, brown trout, fine-spotted Snake River cutthroat trout, and rainbow trout, (2) measure light intensity within open versus shaded reaches during the day, dusk, and night in 3 high-elevation mountain streams, and (3) review the literature on the diel activity of trout.

\section{METHODS}

\section{Laboratory Tests of Scotopic Sensitivity}

All fish used in this study, as in other studies on trout vision (e.g., Allen et al. 1973), were raised in fish hatcheries (2 in Wyoming and 1 in Colorado) because differences in the rearing environment in a natural setting might have led to variation in scotopic sensitivity. We selected hatcheries with similar temperatures $\left(12^{\circ}-\right.$ $15^{\circ} \mathrm{C}$ ), water depths, water quality, food type, and structure (open raceways) to minimize environmental effects on differences in scotopic vision. None of the hatcheries were shaded. We selected fish of each species within the same size range $(25-30 \mathrm{~cm})$ because the number of visual receptors (rods and cones) and the concentration of scotopic pigments (rhodopsin and porphyropsin) increase as trout grow, making larger fish more sensitive to dim light than smaller fish (e.g., Allen et al. 1982).

We determined the scotopic sensitivity of 30 adult fish from each of the 4 salmonid species by recording the intensity of light at which individual fish first responded to a hand breaking the path of light directly overhead or to food floating at the surface of the water (hatchery pellets, Purina Trout Chow). Fish appeared to be startled by hand waving, which creates a shadow over the entire retina that can be perceived without highly acute vision. This startle response to hand waving should occur at lower light levels than a response that requires some level of acuity, such as the detection and location of drifting food. Also, trout may fail to respond to food after visual detection, even when they are starved, because of differences in individual behavior, whereas hand waving will elicit a consistent reaction, as if to a predator, and should provide a less variable signal of the threshold number of photons striking the retina to excite vision and a subsequent response. 


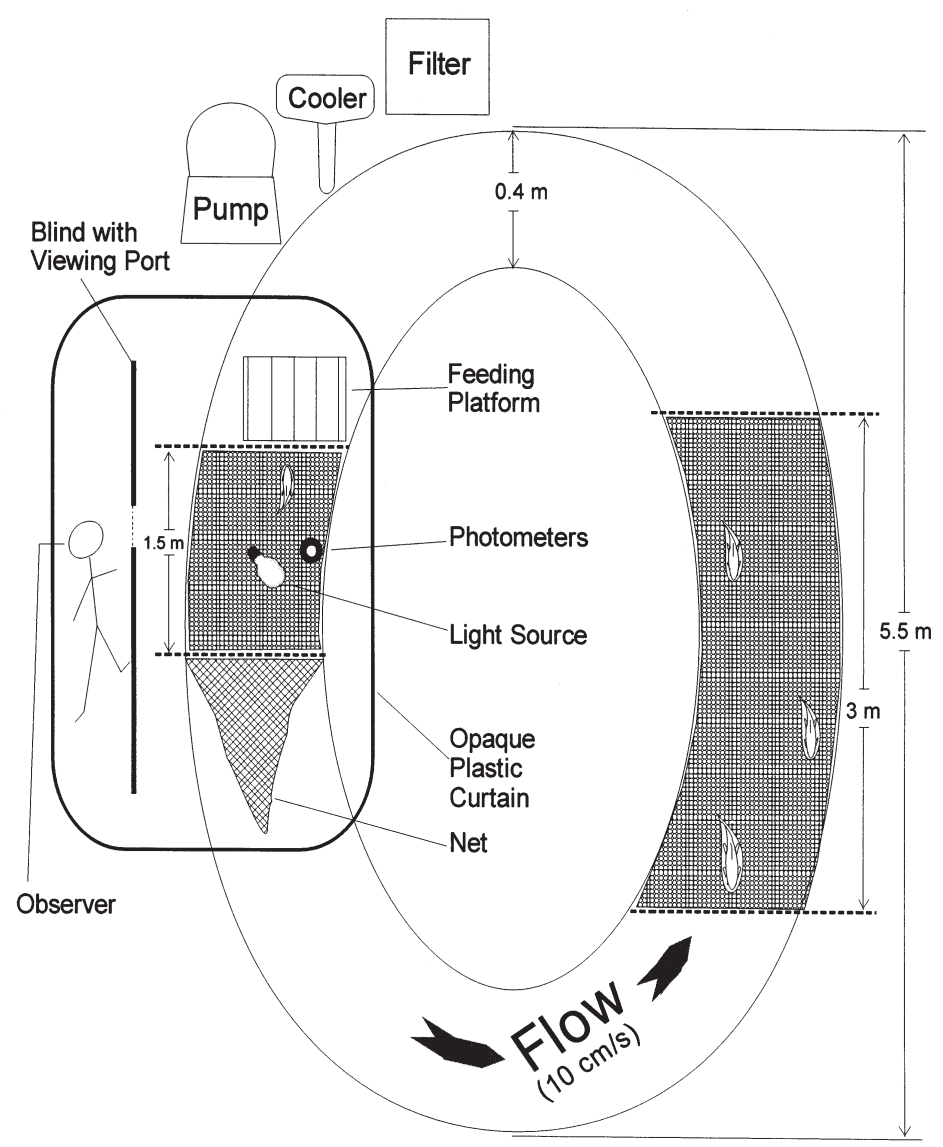

Fig. 1. Laboratory set-up for determining the maximum scotopic sensitivity of brook trout (Salvelinus fontinalis), brown trout (Salmo trutta), fine-spot Snake River cutthroat trout (Oncorhynchus clarki bouvieri), and rainbow trout (Oncorhynchus mykiss).

These experiments were conducted in an oval recirculating laboratory stream (Frigidunits Inc., Toledo, $\mathrm{OH}$, www.frigidunits.com; Fig. 1). The experimental and nonexperimental sections were layered with natural gravels obtained from Nash Fork Creek in Wyoming. Water depth was $30 \mathrm{~cm}$, current velocity $10 \mathrm{~cm} \cdot \mathrm{s}^{-1}$, and temperature $13^{\circ}-15^{\circ} \mathrm{C}$. The stream was housed in a large room enclosed in a warehouse to block extraneous light. A window was blocked with three layers of black plastic during experimental observations. The laboratory stream, including the tent where we stood to make observations, was also enclosed in 3 layers of black plastic (Fig. 1). Observers were separated from the experimental section of the artificial stream by 3 additional layers of black plastic with a cutout viewing port $(25 \times 40 \mathrm{~cm})$. Fish were observed and instruments were read under complete darkness with the aid of a handheld infrared flashlight $(1000 \mathrm{~nm}-0.01 \mathrm{~cm})$ and nightscope (model 260, ITT G3 Night Mariner Binoculars, www.ittnv.com) that magnified light ranging from $400 \mathrm{~nm}$ to $0.01 \mathrm{~cm}$ to 50,000 times brighter than ambient. Fish cannot see in the infrared spectrum (Ali 1961) and thus are not disturbed when observed with infrared radiation (Fraser et al. 1993).

We connected 2 custom-made dim-light sensors (Skye Instruments Ltd., Wales, U.K., www.skyeinstruments.com), 1 that measured total illuminance and 1 that measured total irradiance, to a data logger (LI-COR 1000, www licor.com) and positioned them $5 \mathrm{~cm}$ above the water's surface to record the light intensity at which fish first responded to hand waving or food. The irradiance sensor had a flat spectral response across the entire range of detectable 
wavelengths $(400-720 \mathrm{~nm})$ and a sensitivity of $2.0 \times 10^{-5} \mu \mathrm{mol} \cdot \mathrm{m}^{-2} \mathrm{~s}^{-1}$ to $1.6 \mu \mathrm{mol} \cdot \mathrm{m}^{-2} \mathrm{~s}^{-1}$, whereas the illuminance sensor had a sensitivity of 0.0001-80 lux with a bell-shaped spectral response curve across the range of wavelengths in this study $(400-720 \mathrm{~nm})$. This range from blue $(400 \mathrm{~nm})$ to deep red $(720 \mathrm{~nm})$ was appropriate for this study because trout cannot see infrared radiation (approximately $>720 \mathrm{~nm}$ ) and because there is very little light $<400 \mathrm{~nm}$ (UV) in the natural environment during twilight or at night after the sun has dropped below the horizon (e.g., Williamson 1995, Rader personal observation). This is also the range of light most available at twilight and at night and is thus the most important range in dim-light studies.

We decided to report part of our results in lux because (1) the lux sensor allowed us to compare our results with previous behavioral studies on the visual response of salmonids (e.g., Robinson and Tash 1979, Mazur and Beauchamp 2003), (2) data from both sensors were highly correlated and provided similar results over the range of wavelengths used in this study $(400-720 \mathrm{~nm})$, and (3) illuminance allowed us to compare our lab results with our field measurements, which were recorded with lux sensors during the daylight hours. The critical information (the maximum scotopic sensitivity of these species) will be reported as both irradiance and illuminance.

Each trial began in complete darkness and light levels were gradually increased at a rate of $22.0 \times 10^{-4} \mu \mathrm{mol} \cdot \mathrm{m}^{-2} \mathrm{~min}^{-1}$ (0.005 lux $\cdot$ $\mathrm{min}^{-1}$ ). We collected preliminary data during 2 sunrises under clear skies in June 1997 to duplicate in the laboratory the natural rate at which light increases. We used our custom-made dimlight sensors to record light intensity every second for 90 minutes before the sun crested the horizon. Values varied between $6.1 \times 10^{-5}$ umol $\cdot \mathrm{m}^{-2} \mathrm{~min}^{-1}\left(0.003 \mathrm{lux} \cdot \mathrm{min}^{-1}\right)$, during the early transition from dark to light, to $2.5 \times$ $10^{-2} \mu \mathrm{mol} \cdot \mathrm{m}^{-2} \mathrm{~min}^{-1}\left(1.2 \mathrm{lux} \cdot \mathrm{min}^{-1}\right)$, as the sky grew progressively lighter. We used the average rate of increase during the 1st and darkest half of the transition from dark to light, which is also consistent with the natural rate of change measured at early twilight (dusk and dawn) by Fraser and Metcalfe (1997). To duplicate the natural rate of irradiance increase in the laboratory, it was necessary to wrap the light source (15-watt incandescent tungsten bulb) in
3 pieces of neutral shade cloth. The light intensity of the bulb was controlled by a computer-operated rheostat (Solar 1000, Niche Engineering) that gradually increased the voltage and the irradiance at the specified rate. A similar method of gradually increasing light intensity to simulate a natural sunrise has been previously designed for a variety of laboratory uses (Allen 1980).

We used an SR9000 spectroradiometer (Macam Photometrics, www.macam.com) to compare the spectral composition of our incandescent bulb to the natural spectrum at dawn, dusk, and night at 3 levels of intensity: $2.0 \times$ $10^{-3} \mathrm{w} \cdot \mathrm{m}^{-2} \mathrm{~nm}^{-1}(\sim 0.5$ lux $), 3.8 \times 10^{-4} \mathrm{w} \cdot$ $\mathrm{m}^{-2} \mathrm{~nm}^{-1}(\sim 0.1$ lux $)$, and $1.89 \times 10^{-4} \mathrm{w} \cdot$ $\mathrm{m}^{-2} \mathrm{~nm}^{-1}(\sim 0.05$ lux $)$. A decrease in voltage at bright intensities can cause the spectrum of incandescent bulbs to change, progressively producing smaller proportions of blue light. However, decreasing the voltage from dim light to lower intensities of dim light did not change the spectrum, which was skewed toward a greater proportion of red light (Fig. 2).

We decided to use an incandescent bulb rather than a full-spectrum fluorescent light because we could gradually increase the intensity of the incandescent bulb using the computer-operated rheostat to simulate a natural dawn. The intensity of full-spectrum lights is often controlled with a wedge-shaped neutral density optic filter (e.g., Sontag 1971). However, this requires immobilizing an animal and restraining it to a specific area, thus precluding behavioral analyses. Also, a preliminary exercise showed that adding or removing single layers of fine shade cloth from a full-spectrum light provided a step-wise increase in light intensity that was too coarse for our objectives.

Each species was tested separately during the same time of year because previous research has shown that trout scotopic visual pigments increase during the winter and that this increase is associated with an increase in nocturnal behavior (e.g., Allen et al. 1982, Rimmer and Paim 1989). Cutthroat trout and brook trout trials were completed during August and September 1997, and rainbow and brown trout trials were completed in August and September 1999. Fish were transported from the hatcheries to our laboratory within 24 hours in a 3000-L aerated tank. Thirty individuals of each species were tested over a 10-day period (3 fish per day). All fish were tested from 09:00 to 16:00 


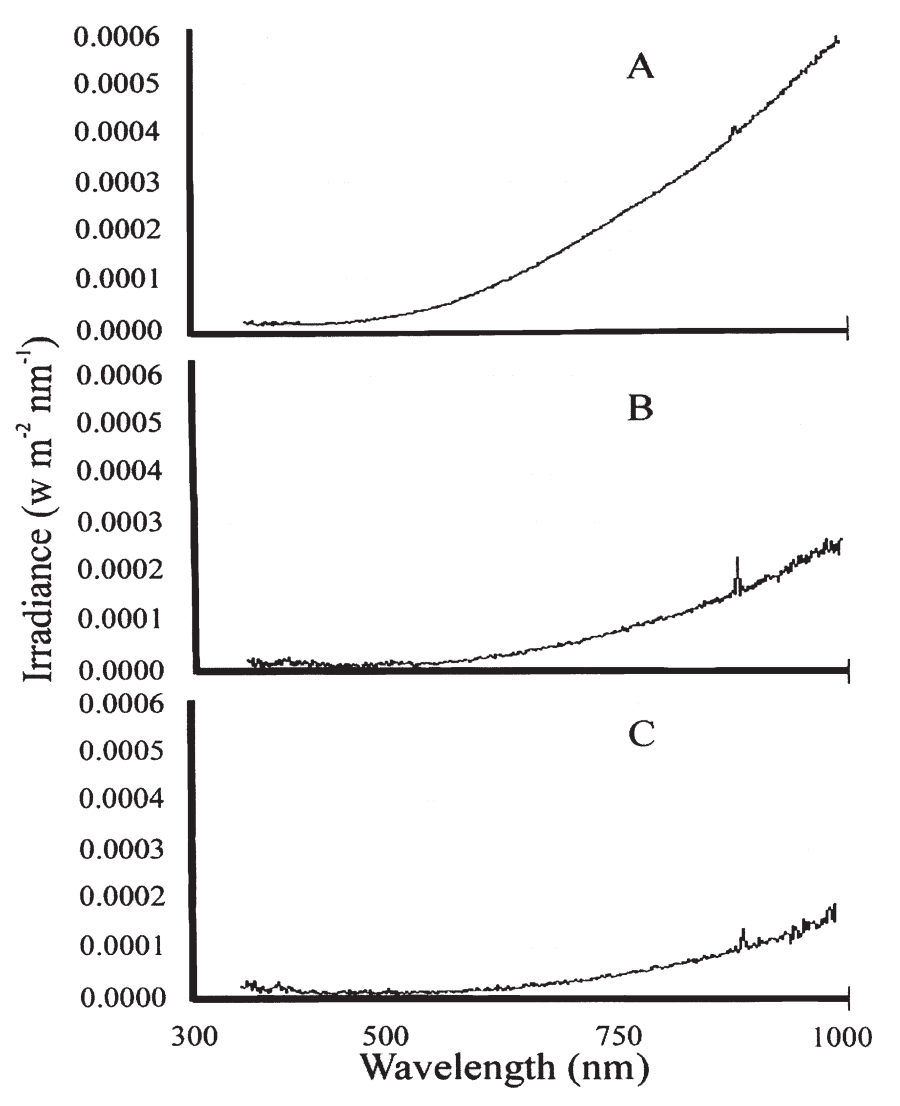

Fig. 2. Spectral composition of our laboratory light source (incandescent bulb) at 3 levels of intensity: $2.0 \times 10^{-3} \mathrm{~W}$. $\mathrm{m}^{-2} \mathrm{~nm}^{-1}, \sim 0.5$ lux $(\mathrm{A}) ; 3.8 \times 10^{-4} \mathrm{w} \cdot \mathrm{m}^{-2} \mathrm{~nm}^{-1}, \sim 0.1$ lux $(B)$; and $1.89 \times 10^{-4} \mathrm{w} \cdot \mathrm{m}^{-2} \mathrm{~nm}^{-1}, \sim 0.05$ lux $(\mathrm{C})$.

during each trial. Before a trial, each fish was starved for 72 hours and dark-adapted for 8 hours. All fish were exposed to a diel cycle of 12 hours of night and 12 hours of day under full-spectrum fluorescent lights for at least 7 days prior to being dark-adapted. Under complete darkness, we removed a single fish from the holding section, placed it in the observation area, and provided a 40-minute acclimation period (Fig. 1). Trials did not begin until each fish was calm and facing upstream. Examining each fish alone eliminated the effects of intraspecific interactions on their behavior, which could cause some fish to fail to respond to a visual signal.

We also needed to determine if these fish could respond to food pellets by olfaction without a visual cue. Therefore, a trial began by adding 2 food pellets every 30 seconds upstream from the experimental section for 3 minutes under complete darkness to ensure that fish could not locate pellets by olfaction. Also, after 3 minutes and 6 feeding possibilities, the smell of food should have initiated a feeding response as the light levels increased. The fish had 15 seconds to locate the food during each 30 -second interval before the pellet exited the experimental section. Every 30 seconds a hand was waved 4 times, without touching the water, directly above the fish. At the 4 th minute, irradiance began to increase $\left(22.0 \times 10^{-4} \mu \mathrm{mol}\right.$. $\mathrm{m}^{-2} \mathrm{~min}^{-1}, 0.005$ lux $\cdot \min ^{-1}$ ), and food additions and waving continued at 30 -second intervals for 20 minutes. After 20 minutes irradiance reached $0.04 \mu \mathrm{mol} \cdot \mathrm{m}^{-2} \mathrm{~s}^{-1}(0.1 \mathrm{lux})$, which is the approximate irradiance of a clear night with a full moon (Contor and Griffith 1995). We used a nightscope to record the light level when a fish first responded to either hand waving or when it first oriented toward and responded to food. In order to prevent disturbing the fish, waving stopped after the 1st response; however, food was added every 30 seconds throughout the 20minute trial. If a fish failed to respond, it was 
replaced with another fish and the trial was rerun.

\section{Field Light Measurements}

We measured light intensity in a shaded reach and in an open reach in 3 Rocky Mountain streams during the day, dusk, and night to estimate the amount of time different species can forage in different reach types. West St. Louis Creek is a 2nd-order tributary of St. Louis Creek, which is a 3rd-order mountain stream draining the USDA Fraser Experimental Forest in Grand County, Colorado (latitude $39^{\circ} 53^{\prime} \mathrm{N}$, longitude $105^{\circ} 54^{\prime} \mathrm{W}$ ). Nash Fork Creek is a 3rdorder stream draining the eastern slope of the Medicine Bow Mountains in Albany County, $65 \mathrm{~km}$ west of Laramie, Wyoming (latitude $41^{\circ} 21^{\prime} \mathrm{N}$, longitude $\left.106^{\circ} 13^{\prime} \mathrm{W}\right)$. Riparian vegetation along shaded stream reaches consisted of lodgepole pine (Pinus contorta), spruce (Picea spp.), and fir (Abies lasiocarpa), but vegetation along reaches with an open canopy was dominated by low-growing willows (Salix spp.) and grasses. All reaches were located at similar elevations ( $\sim 2800 \mathrm{~m}$ asl), and the open reaches were downstream from and adjacent to the steeper, shaded reaches.

We used our custom-made low light sensors (lux and $\mu \mathrm{mol} \cdot \mathrm{m}^{-2} \mathrm{~min}^{-1}$ ) to measure dim levels of light (last part of dusk and night) and a standard bright-light lux sensor (LI-210, LICOR Biosciences, www.licor.com) to measure illumination during the day and the 1st part of dusk. Although we were interested in dim-light differences in light intensity, the bright-light lux sensors $(400-720 \mathrm{~nm})$ were included to show relative differences between shaded and open reaches. Thus, dim and bright readings were expressed in lux because we only had lux sensors for bright light.

We evaluated light intensity with respect to (1) time of day, (2) cloudiness, (3) the lunar cycle, and (4) shading by riparian vegetation. Light intensity was measured during day (11:00-18:00), dusk (19:30-21:30), and night (23:00-02:00) once a week for 7 weeks (July and August 1999) at 3 stations in the shaded reaches and 3 in the open reaches in each stream. The mean, minimum, and maximum light intensity was recorded at each station every 5 seconds for six 15 -second intervals evenly spaced over a 20 -minute period during the times indicated above. The weather (e.g., cloudy versus clear) was noted during each period at each station, and nighttime intensity was measured during each phase of the lunar cycle (no moon, part moon, or full moon). Sensors were leveled in the same position on the bank $0.5 \mathrm{~m}$ from the surface of the water at each station on each sampling date. These cylindrical sensors primarily detect light from directly overhead, which was appropriate because light arriving directly from its source (moon and stars) constitutes the majority of the total intensity at night (Endler 1993).

The averages of flow, width, percent shade, gradient, and maximum pool depth were calculated for each reach in each stream. Average percent shading was digitally calculated using photographs taken from the same height (1.83 $\mathrm{m}$ ) in the middle of the stream with a wideangle lens aimed directly overhead into the canopy at 6 locations in each reach.

\section{Literature Review on the Diel Activity of Trout}

We reviewed the literature describing the diel activity of trout because differences in the time at which fish are most active should reflect differences in scotopic visual sensitivity. For each study we recorded the primary period(s) of activity and indicated the strength of evidence supporting the conclusions. Results from casual or haphazard observational data were less conclusive than systematic 24-hour observations, day versus night gut analyses, tracking of 24-hour activity patterns using radiotelemetry, or laboratory experimental data.

\section{Statistical Analysis}

A 1-way ANOVA and Tukey's multiple comparison tests (SAS Institute, Inc. 1997) with 4 levels (salmonid species) were used to compare the average light intensity of the 1st response of individual fish to either hand waving or food in our laboratory experiment. Tests for normality and homoscedasticity indicated that the data were skewed for 2 of the 4 species. Therefore, analyses were run after a $\log _{\mathrm{e}}$ transformation.

\section{RESULTS \\ Laboratory Tests of Scotopic Visual Sensitivity}

No fish responded to food (or waving) during the 3-minute dark phase at the beginning of each trial. This indicated that subsequent 
TABLE 1. Physical attributes of shaded and open reaches in 3 Rocky Mountain streams.

\begin{tabular}{|c|c|c|c|c|c|c|}
\hline & \multicolumn{2}{|c|}{ St. Louis Creek } & \multicolumn{2}{|c|}{ West St. Louis Creek } & \multicolumn{2}{|c|}{ Nash Fork Creek } \\
\hline & Shaded & Open & Shaded & Open & Shaded & Open \\
\hline Mean flow $\left(\mathrm{m}^{3} \cdot \mathrm{s}^{-1}\right)$ & 0.093 & 0.098 & 0.039 & 0.055 & 0.072 & 0.068 \\
\hline Mean bankfull width (cm) & 687 & 1740 & 273 & 320 & 635 & 830 \\
\hline Mean percent shade & 41 & 0 & 70 & 0 & 64 & 0 \\
\hline Mean gradient $(\%)$ & 2.1 & 1.5 & 3.1 & 1.7 & 3.6 & 0.6 \\
\hline Mean maximum pool depth $(\mathrm{cm})$ & 51 & 59 & 29 & 45 & 34 & 63 \\
\hline
\end{tabular}

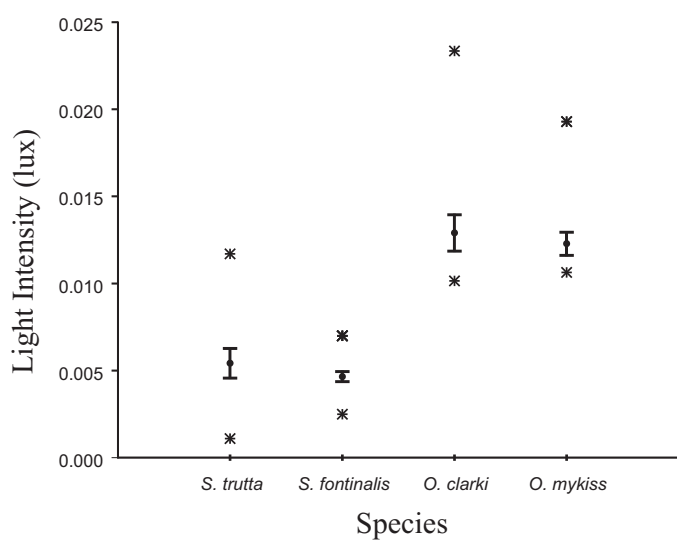

Fig. 3. Differences in the mean maximum scotopic sensitivity of 4 species of trout. Bars represent 1 standard error about the mean, and stars are the extreme high and low responses of individual trout within each species.

responses as light intensity increased were visual and not olfactory. Twelve fish (2 cutthroat trout, 4 brown trout, and 6 brook trout) out of 120 failed to respond during this experiment, and each was replaced by another fish. As expected, all 4 species were startled and reacted first to waving rather than food. Thirty-eight percent of the fish did not feed at any point during a trial, although $21 \%$ rose to a floating pellet without actually feeding. Because of this variation we did not analyze their response to food as a reliable indication of the maximum dim-light intensities at which these species could first detect food floating at the surface. However, the dim-light threshold showing a startle response was consistent across each species. Thus, the startle response was the basis for our dim-light comparisons in this study.

The irradiance at which fish first reacted to waving was significantly lower $\left(F_{3,116}=64, P\right.$ $<0.0001)$ for brown trout and brook trout than for cutthroat trout and rainbow trout (Fig. 3). The average light intensity of the 1st response of brown trout $\left(1.1 \times 10^{-4} \mu \mathrm{mol} \cdot \mathrm{m}^{-2} \mathrm{~s}^{-1}\right.$, $\sim 0.0054$ lux $)$ and brook trout $\left(9.4 \times 10^{-5}\right.$ umol . $\mathrm{m}^{-2} \mathrm{~s}^{-1}, \sim 0.0047$ lux) was approximately half that of cutthroat trout $\left(2.5 \times 10^{-4}\right.$ umol . $\left.\mathrm{m}^{-2} \mathrm{~s}^{-1}, \sim 0.013 \mathrm{lux}\right)$ and rainbow trout $(2.2 \times$ $\left.10^{-4} \mu \mathrm{mol} \cdot \mathrm{m}^{-2} \mathrm{~s}^{-1}, \sim 0.012 \mathrm{lux}\right)$. The brightest intensity at which brook trout first responded $\left(1.5 \times 10^{-4} \mu \mathrm{mol} \cdot \mathrm{m}^{-2} \mathrm{~s}^{-1}, \sim 0.0068\right.$ lux $)$ was less than the dimmest intensity at which cutthroat trout $\left(1.9 \times 10^{-4} \mu \mathrm{mol} \cdot \mathrm{m}^{-2} \mathrm{~s}^{-1}, \sim 0.01\right.$ lux) and rainbow trout $\left(1.9 \times 10^{-4} \mu \mathrm{mol}\right.$. $\mathrm{m}^{-2} \mathrm{~s}^{-1}, \sim 0.01$ lux) first responded (Fig. 3). Also, brown trout's first response was at a dimmer light level $\left(2.36 \times 10^{-4} \mu \mathrm{mol} \cdot \mathrm{m}^{-2} \mathrm{~s}^{-1}\right.$, $\sim 0.00012$ lux) than for any of the other fishes' first responses, whereas cutthroat trout's first response was at the brightest $\left(4.2 \times 10^{-4} \mu \mathrm{mol}\right.$. $\mathrm{m}^{-2} \mathrm{~s}^{-1}, \sim 0.02$ lux).

The spectral composition of our lab light was shifted toward longer wavelengths: orange and especially red (Fig. 2). Blue and green wavelengths were poorly represented. Thus, differences in dim-light sensitivity between the 4 species in this study are based primarily on their response to light with longer wavelengths.

\section{Field Light Measurements}

As expected, shading and light intensity varied by stream and time of day (Fig. 4). St. Louis Creek was the largest stream and had the least shade, whereas West St. Louis Creek and Nash Fork Creek were smaller with a dense canopy over the shaded reaches (Table 1). Pool depth is important because most trout in these streams (brook trout) reside in pools and because light can rapidly attenuate with an increase in water depth (e.g., Wetzel 2001). However, there were no pools deeper than $75 \mathrm{~cm}$ in any of the reaches, and most were $<60 \mathrm{~cm}$ deep. Thus, our light sensors, which were positioned just above the surface of the water, provided a good estimate of the relative differences in the light available to fish in the different reaches.

Light intensity varied 9 orders of magnitude between extreme conditions: a clear sunny day 


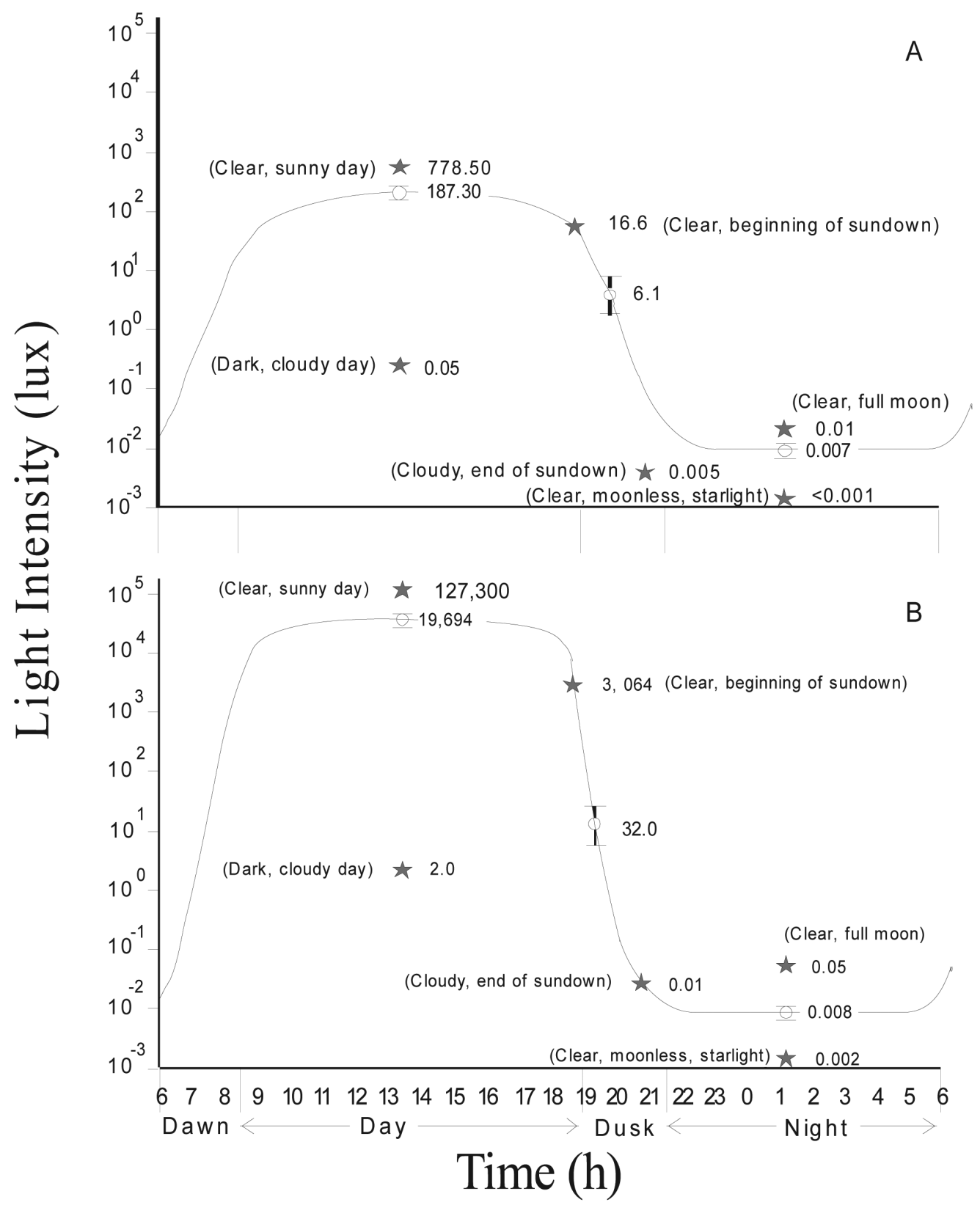

Fig. 4. Mean differences in light intensity during the day, dusk, and night between reaches with a closed (A) and open (B) canopy in 3 mountain streams. Bars represent 1 standard error about the mean, and stars are the extreme high and low values for each period. The line is a generalized curve for a 24 -hour period.

in the open versus a clear moonless night in the shade. However, the level of starlight on a clear moonless night in the shade was below the detection limit of our dim-light sensors. Average irradiance at dusk and the brightest nighttime conditions (clear, full moon) were both 5 times greater in the open than in the shade (Fig. 4).
As expected, cloudiness greatly reduced irradiance in both open and shaded reaches. Contrary to expectations, however, average light intensities at night were similar in the open and shaded reaches $\left(1.61 \times 10^{-4} \mu \mathrm{mol} \cdot \mathrm{m}^{-2} \mathrm{~s}^{-1}\right.$, $\sim 0.008$ lux and $1.47 \times 10^{-4} \mu \mathrm{mol} \cdot \mathrm{m}^{-2} \mathrm{~s}^{-1}$, $\sim 0.007$ lux, respectively) because, by chance, 
we made more nighttime measurements under cloudy conditions in the open than in the shade. Our results are consistent with the summary provided by Contor and Griffith (1995) in which the intensity of starlight and moonlight in the open can vary between 0.0005 lux and 0.001 lux and between 0.05 lux and 1.0 lux, respectively.

\section{Trout Diel Activity}

We found 28 studies that reported the diel activity of brown trout, 23 for cutthroat trout and rainbow trout, and 10 for brook trout (Table 2). Brown trout and brook trout had the most frequent occurrence of activity under dim-light conditions. Seventy-five percent of the studies reported twilight and/or nocturnal activity for brown trout, $70 \%$ for brook trout, and 39\% for cutthroat trout + rainbow trout. Also, brown trout had the highest percentage of reported nighttime activity (64\%) followed by brook trout $(30 \%)$ and cutthroat trout + rainbow trout $(13 \%)$.

\section{DisCUSSION}

We have shown that the maximum scotopic threshold of brown trout and brook trout was more sensitive than that of cutthroat trout and rainbow trout. Confounding factors did not compromise these results because all of these fish were (1) raised in hatcheries under similar light conditions, (2) similar in size, and (3) tested during the same season at the same temperatures. Also, these results were generally supported by our literature review in that a greater percentage of studies reported dim-light activity for brown trout and brook trout than for cutthroat trout and rainbow trout, which were primarily diurnal. Brook trout and brown trout had average scotopic thresholds near $1.0 \times$ $10^{-4} \mu \mathrm{mol} \cdot \mathrm{m}^{-2} \mathrm{~s}^{-1}(\sim 0.005 \mathrm{lux})$, whereas Snake River cutthroat trout and rainbow trout had average thresholds near $2.0 \times 10^{-4}$ umol $\cdot \mathrm{m}^{-2} \mathrm{~s}^{-1}(\sim 0.01$ lux $)$. These thresholds underestimated the scotopic sensitivity of these fish because intensity was measured near the surface of the water and not in the water where the fish were swimming. However, actual thresholds should be only slightly lower because the water in our experimental stream was shallow, clear, and produced a minimum amount of attenuation.

The light source in our laboratory experiment was skewed toward longer wavelengths of orange and especially red at all of the dimlight intensities used in this study. Thus, in order to place these findings in their correct environmental context, we need to discuss the availability of light with longer wavelengths under dim-light conditions in the natural environment. That is, the application of our lab results to a natural setting depends on whether the predominant wavelengths in the field under dim light (twilight, moonlight, starlight) are often skewed toward longer wavelengths, especially red.

Although longer wavelengths attenuate rapidly with increasing water depth (Wetzel 2001), red light should be plentiful in most mountain streams because fish habitats (pools and runs) are often $<50 \mathrm{~cm}$ deep. In distilled water, $50 \%$ of red light remains at approximately $1 \mathrm{~m}$ in depth (Wetzel and Likens 1991). Thus, $75 \%$ or more of the ambient red light should remain after attenuation in most pool habitats in these streams.

During twilight as the sun approaches and initially drops below the horizon the spectrum is skewed towards red and blue light with a $33 \%$ reduction in green, yellow, and orange light (Johnson et al. 1966, McFarland and Munz 1976). However, as the sun continues to drop below the horizon, red light decreases and the spectrum becomes increasingly blue because blue light is the dominant color of skylight. Thus, early twilight is dominated by red light directly from the sun and blue skylight, and late twilight is dominated by blue skylight unless there are clouds overhead. Reddish light from the setting sun will reflect off of the undersurface of clouds onto the surface of a stream, prolonging the period when wavelengths are skewed toward red (Endler 1993). Clouds produce a flat, white spectrum on the surface of a stream only if the sun shines through them from above (McFarland and Munz 1976, Endler 1993).

Although the moon reflects sunlight and has a fairly flat spectrum, it is enriched in red wavelengths relative to full sunlight (McFarland and Munz 1976). Also, when the moon is low on the horizon, its light must pass through more of the Earth's atmosphere, causing an additional shift towards the red end of the spectrum. The spectrum of starlight is also skewed toward red wavelengths (Munz and McFarland 1973). Additionally, McFarland and Munz (1976) measured the daylight spectrum of Carrabelle River 
TABLE 2. Literature review of the diel activity of several salmonid species. Strength of evidence is recorded in the last column $(1=$ haphazard observational data, $3=$ systematic observational data $/$ diel gut analysis, $5=$ telemetry/ experimental data).

\begin{tabular}{|c|c|c|c|}
\hline Species & Diel periodicity & Citation & Evidence \\
\hline Oncorhynchus apache & Diurnal & Robinson and Tash 1979 & 5 \\
\hline Oncorhynchus clarki & Diurnal & Griffith 1974 & 1 \\
\hline O. clarki & Diurnal & Edmundson et al. 1968 & 1 \\
\hline O. clarki pleuriticus & Diurnal & Young et al. 1997a & 5 \\
\hline O. clarki clarki & Nocturnal & Schutz and Northcote 1972 & 5 \\
\hline Oncorhynchus mykiss & Crepuscular & Newman 1956 & 1 \\
\hline O. mykiss & Crepuscular & Elliott 1970 & 3 \\
\hline O. mykiss & Crepuscular & Elliott 1973 & 3 \\
\hline O. mykiss & Crepuscular & Douglas 1982 & 5 \\
\hline O. mykiss & Crepuscular & Jenkins et al. 1970 & 5 \\
\hline O. mykiss & Crepuscular & Landless 1976 & 5 \\
\hline O. mykiss & Diurnal & Edmundson et al. 1968 & 1 \\
\hline O. mykiss & Diurnal & Eggers 1977 & 1 \\
\hline O. mykiss & Diurnal & Hoar 1953 & 1 \\
\hline O. mykiss & Diurnal & Angradi and Griffith 1990 & 3 \\
\hline O. mykiss & Diurnal & Tippets and Moyle 1978 & 3 \\
\hline O. mykiss & Diurnal & Campbell and Neuner 1985 & 3 \\
\hline O. mykiss & Diurnal & Young et al. 1997a & 5 \\
\hline O. mykiss & Diurnal & Bisson 1978 & 5 \\
\hline O. mykiss & Diurnal & Boujard and Leatherland 1992 & 5 \\
\hline O. mykiss & Fed at light levels $>0.035$ lux & Tanaka 1970 & 5 \\
\hline O. mykiss & Nocturnal & Elliott 1973 & 3 \\
\hline O. mykiss & Nocturnal & Jenkins 1969 & 5 \\
\hline Salvelinus alpinus & Nocturnal & Dervo et al. 1991 & 3 \\
\hline Salvelinus fontinalis & Crepuscular & Newman 1956 & 1 \\
\hline S. fontinalis & Crepuscular & Boisclair 1992 & 3 \\
\hline S. fontinalis & Crepuscular & Hoar 1942 & 5 \\
\hline S. fontinalis & Crepuscular & Gibson and Keenleyside 1966 & 5 \\
\hline S. fontinalis & Diurnal & Griffith 1974 & 1 \\
\hline S. fontinalis & Diurnal/crepuscular & Allan 1981 & 3 \\
\hline S. fontinalis & Continuously active & Rader unpublished data & 3 \\
\hline Salvelinus malma & Diurnal & Edmundson et al. 1968 & 1 \\
\hline S. malma & Nocturnal & Schutz and Northcote 1972 & 5 \\
\hline Salmo salar & Crepuscular & Hoar 1942 & 5 \\
\hline S. salar & Diurnal & Fraser et al. 1993 & 5 \\
\hline S. salar & Diurnal & Gibson and Keenleyside 1966 & 5 \\
\hline Salmo trutta & Continuously active & Tuša 1968 & 1 \\
\hline S. trutta & Continuously active & McIntosh and Townsend 1995 & 5 \\
\hline S. trutta & Continuously active & Oswald 1978 & 5 \\
\hline S. trutta & Crepuscular & Eriksson 1978 & 1 \\
\hline S. trutta & Crepuscular & McCormack et al. 1989 & 5 \\
\hline S. trutta & Diurnal & Bachman 1984 & 3 \\
\hline S. trutta & Diurnal & Borja et. al 1990 & 5 \\
\hline S. trutta & Diurnal/crepuscular & Swift 1962 & 3 \\
\hline S. trutta & Diurnal/crepuscular & Swift 1964 & 3 \\
\hline S. trutta & Diurnal/crepuscular & Elliott 1970 & 3 \\
\hline S. trutta & Nocturnal & Brynildson et al. 1963 & 1 \\
\hline S. trutta & Nocturnal & Butler and Hawthorne 1968 & 1 \\
\hline S. trutta & Nocturnal & Jenkins 1969 & 1 \\
\hline S. trutta & Nocturnal & Lewis 1969 & 1 \\
\hline S. trutta & Nocturnal & Dervo et al. 1991 & 3 \\
\hline S. trutta & Nocturnal & Shuler et al. 1994 & 3 \\
\hline S. trutta & Nocturnal & Chaston 1968 & 3 \\
\hline S. trutta & Nocturnal & Chaston 1969 & 3 \\
\hline S. trutta & Nocturnal & Elliott 1967 & 3 \\
\hline S. trutta & Nocturnal & Elliott 1973 & 3 \\
\hline S. trutta & Nocturnal & Young et al. 1997b & 5 \\
\hline S. trutta & Nocturnal & Clapp et al. 1990 & 5 \\
\hline S. trutta & Nocturnal & Schutz and Northcote 1972 & 5 \\
\hline S. trutta & Nocturnal & Robinson and Tash 1979 & 5 \\
\hline
\end{tabular}


in Florida and found that there was no light with a wavelength shorter than $600 \mathrm{~nm}$ during the day in this blackwater river. This redshift is caused by plant leachates (e.g., tannins) that are often abundant in the groundwater associated with stream ecosystems. Thus, the prevalence of a red-shifted spectrum in streams may also depend on the concentration of plant leachates in the groundwater and the amount of groundwater inflow. Overall, this information suggests that dim-light conditions in streams are often skewed toward red wavelengths. Thus, our lab results do represent differences in sensitivity between these species under frequent natural conditions. However, we cannot eliminate the possibility that the variation in scotopic sensitivity among these species could change if similar lab studies were conducted with predominantly blue light.

Trout are visual predators, and light is one of the most important factors determining prey detection (e.g., Wilzbach et al. 1986, Forrester et al. 1994). Over a 24 -hour period, trout with sensitive scotopic vision will be able to forage longer than trout with poor scotopic sensitivity. Species with better dim-light vision could have higher 24-hour rates of consumption. Because food may limit trout populations (Chapman 1966, Richardson 1993), higher rates of consumption could produce faster growth and greater fecundity. The light intensity necessary to invoke a startle response was 2 times lower in brown trout and brook trout than in Snake River cutthroat trout and rainbow trout. Our literature review showed that cutthroat trout and rainbow trout were primarily active during the day, which suggests that cutthroat trout as a group may have poorer scotopic vision than brook trout or brown trout. If so, these 2 species may be able to forage longer over a 24 -hour period and during the course of a growing season than most, if not all, cutthroat lineages. This may partially explain how brook trout and brown trout exclude most cutthroat trout populations in many mountain streams of the western United States (e.g., Behnke 1992).

Adult brook trout and brown trout spawn in the fall, and young fish hatch early in the spring, giving them a size advantage over the fry of cutthroat trout, which spawn during the spring and hatch later in the summer (e.g., Behnke 1992). For a variety of reasons, large body size is an important factor in determining differences in the fitness of stream salmonids (e.g., Fausch
1984, McIntosh et al. 1994). The ability of brook trout and brown trout to feed longer over a 24hour period may allow them to sustain or even increase this initial size advantage, which allows them to maintain a greater overall fitness than cutthroat trout. This fitness advantage may be the best explanation for how introduced trout (brook trout and brown trout) can cause the local extirpation of native cutthroat trout.

Native cutthroat trout may be better able to compete with introduced trout in open reaches because brighter light intensities may reduce the foraging advantage of brook trout and brown trout. Light intensities from mid-twilight to a moonless, starlit night were about 5 times greater in open reaches than in shaded reaches of this study. In open reaches, cutthroat trout may be able to forage longer with greater efficiency during the growing season than in darker, shaded reaches. This suggestion is consistent with the observation that coastal cutthroat trout foraging efficiency and abundance were greater in logged headwater streams of the Oregon Cascades than in reaches shaded by stands of mature riparian vegetation (Hawkins et al. 1983, Wilzbach and Cummins 1986). If so, native cutthroat trout restoration efforts may have greater success in open versus shaded stream reaches in the Rocky Mountains and elsewhere.

Future research should extend the application of our results on the scotopic sensitivity of Snake River cutthroat trout to all cutthroat lineages. It should examine the underlying physiological mechanisms explaining differences in scotopic sensitivity among these species. Also, future research should explore the relationship between the maximum scotopic threshold of cutthroat trout, their foraging efficiency, and their overall fitness versus that of introduced trout in open and shaded reaches.

\section{ACKNOWLEDGMENTS}

We are grateful for the dedication of our undergraduate research assistants-Ken Ayres, Galen Cook, Andy Davis, and Valerie Masonin helping to gather the field light data. Clinton R. Rader donated numerous hours of volunteer work. William N. McFarland made helpful comments at the outset of this study, and Robert R. McDougal (U.S. Geological Survey) provided spectral analysis of our laboratory light source. This work was sponsored by the Rocky 
Mountain Forest and Range Experiment Station of the USDA Forest Service and the Department of Integrative Biology at Brigham Young University.

\section{Literature Cited}

ALI, M.A. 1961. Histophysiological studies on the juvenile Atlantic salmon (Salmo salar) retina. Canadian Journal of Zoology 39:511-525.

ALLAN, J.D. 1981. Determinants of diet of brook trout (Salvelinus fontinalis) in a mountain stream. Canadian Journal of Fisheries and Aquatic Sciences 38:184192

ALlen, D.M. 1980. A device providing gradual transitions between light and dark periods in the animal room. Laboratory Animal Science 30:252-254.

Allen, D.M., E.R. Loew, and W.N. McFarland. 1982. Seasonal changes in the amount of visual pigment in the retinae of fish. Canadian Journal of Zoology 60:281-287.

Allen, D.M., W.N. McFarland, F.W. Munz, and H.A. Poston. 1973. Changes in the visual pigments of trout. Canadian Journal of Zoology 51:901-914.

Angradi, T.R., and J.S. Griffith. 1990. Diel feeding chronology and diet selection of rainbow trout (Oncorhynchus mykiss) in the Henry's Fork of the Snake River, Idaho. Canadian Journal of Fisheries and Aquatic Sciences 47:199-209.

BaChman, R.A. 1984. Foraging behavior of free-ranging wild and hatchery brown trout in a stream. Transactions of the American Fisheries Society 113:1-32.

BEHNKE, R.J. 1992. Native trout of Western North America. American Fisheries Society, Monograph 6, Bethesda, MD.

Bisson, P.A. 1978. Diel food selection by two sizes of rainbow trout (Salmo gairdneri) in an experimental stream. Journal of the Fisheries Research Board of Canada 35:971-975.

BoIsClair, D. 1992. Relationship between feeding and activity rates for actively foraging juvenile brook trout (Salvelinus fontinalis). Canadian Journal of Fisheries and Aquatic Sciences 49:2566-2573.

Borja, M.M., E. Perez, R. Pupier, and B. Buisson. 1990. Entrainment of the circadian activity rhythm in the juvenile trout, Salmo trutta, by red light. Journal of Interdisciplinary Cycle Research 21:81-89.

Boujard, T., AND J.F. LeatherLand. 1992. Demand-feeding behaviour and diel pattern of feeding activity in Onchorhynchus mykiss held under different photoperiod regimes. Journal of Fish Biology 40:535-544.

Bowmaker, J.K. 1990. Visual pigments of fishes. Pages 81-104 in R.H. Douglas and M.B.A. Djamgoz, editors, The visual system of fish. Chapman and Hall, New York.

BOWMAKER, J.K., AND Y.W. KUNZ. 1987. Ultraviolet receptors, tetrachromatic colour vision and retinal mosaics in the brown trout (Salmo trutta): age-dependent changes. Vision Research 27:2101-2108.

Brynildison, O.M., V.A. Hacker, and T.A. KLICK. 1963. Brown trout-its life history, ecology, and management. Wisconsin Conservation Report 234.

ButLER, R.L., AND V.M. HaWTHORNE. 1968. The reactions of dominant trout to changes in overhead artificial cover. Transactions of the American Fisheries Society 97:37-41.

Campbell, R.F., and J.H. Neuner. 1985. Seasonal and diurnal shifts in habitat utilized by resident rainbow trout in western Washington Cascade Mountain streams. Pages 39-49 in Symposium on small hydropower and fisheries.

Chapman, D.W. 1966. Food and space as regulators of salmonid populations in streams. American Naturalist 100:345-357.

Chaston, I. 1968. Influence of light on activity of brown trout (Salmo trutta). Journal of the Fisheries Research Board of Canada 25:1285-1289.

1969. Seasonal activity and feeding pattern of brown trout (Salmo trutta) in a Dartmoor stream in relation to availability of food. Journal of the Fisheries Research Board of Canada 26:2165-2171.

Clapp, D.F., R.D. ClakK, and J.S. Diana. 1990. Range, activity, and habitat of large, free-ranging brown trout in a Michigan stream. Transactions of the American Fisheries Society 119:1022-1034.

Confer, J.L., G.L. Howick, M.H. Kramer, S.L. FitzgibBON, AND R. LANDESBERG. 1978. Visual predation by planktivores. Oikos 31:27-37.

Contor, C.R., AND J.S. Griffith. 1995. Nocturnal emergence of juvenile rainbow trout from winter concealment relative to light intensity. Hydrobiologia 299: 179-183.

Coughlin, D.J., and C.W. Hawryshyn. 1995. A cellular basis for polarized-light vision in rainbow trout. Journal of Comparative Physiology 176:261-272.

Dervo, B.K., O. Hegget, D.O. Hessen, and J. Skurdal. 1991. Diel food selection of pelagic Arctic charr, Salvelinus alpinus (L.), and brown trout, Salmo trutta L., in Lake Atnsjo, SE Norway. Journal of Fish Biology 38:199-209.

Deutschlander, M.E., D.K. Greaves, T.J. Haimberger, and C.W. Hawryshyn. 2001. Functional mapping of ultraviolet photosensitivity during metamorphic transitions in a salmonid fish, Oncorhynchus mykiss. Journal of Experimental Biology 204:2401-2413.

DougLas, R.H. 1982. An endogenous crepuscular rhythm of rainbow trout (Salmo gairdneri) photomechanical movements. Journal of Experimental Biology 96: $377-388$.

Douglas, R.H., AND C.W. Hawryshyn. 1990. Behavioural studies of fish vision: an analysis of visual capabilities. Pages 373-418 in R.H. Douglas and M.B.A. Djamgoz, editors, The visual system of fish. Chapman and Hall, New York.

Edmundson, E., F.E. Everest, and D.W. Chapman. 1968. Permanence of station in juvenile chinook salmon and steelhead trout. Journal of the Fisheries Research Board of Canada 25:1453-1464.

EgGERS, D.M. 1977. The nature of prey selection by planktivorous fish. Ecology 58:46-59.

ElliotT, J.M. 1967. The food of trout (Salmo trutta) in a Dartmoor stream. Journal of Applied Ecology 4:59-71. 1970. Diel changes in invertebrate drift and the food of trout Salmo trutta L. Journal of Fish Biology 2:161-165.

1973. The food of brown and rainbow trout (Salmo trutta and S. gairdneri) in relation to the abundance of drifting invertebrates in a mountain stream. Oecologia 12:329-347. 
Endler, J.A. 1993. The color of light in forests and its implications. Ecological Monographs 63:1-27.

Eriksson, L.-O. 1978. Nocturnalism versus diurnalism: dualism within fish individuals. Pages 69-89 in J.E. Thorpe, editor, Rhythmic activity in fishes. Academic Press, London.

Fausch, K.D. 1984. Profitable stream positions for salmonids: relating specific growth rate to net energy gain. Canadian Journal of Zoology 62:441-451.

Forrester, G.E., J.G. Chace, and W. MCCarthy. 1994. Diel and density-related changes in food consumption and prey selection by brook char in a New Hampshire stream. Environmental Biology of Fishes 39:301-311.

Fraser, N.H., and N.B. Metcalfe. 1997. The cost of becoming nocturnal: feeding efficiency in relation to light intensity in juvenile Atlantic Salmon. Functional Ecology 11:385-391.

Fraser, N.H., N.B. Metcalfe, and J.E. Thorpe. 1993. Temperature-dependent switch between diurnal and nocturnal foraging in salmon. Proceedings. Royal Society of London. Series B. Biological Sciences 252: 135-139.

Gibson, R.J., AND M.H.A. KeEnLEyside. 1966. Responses to light of young Atlantic salmon (Salmo salar) and brook trout (Salvelinus fontinalis). Journal of the Fisheries Research Board of Canada 23:1007-1024.

Griffith, J.S., JR. 1974. Utilization of invertebrate drift by brook trout (Salvelinus fontinalis) and cutthroat trout (Salmo clarki) in small streams in Idaho. Transactions of the American Fisheries Society 3:440-447.

Hawkins, C.P., M.L. Murphy, N.H. Anderson, and M.A. WilzBaCH. 1983. Riparian canopy and substrate composition interact to influence the abundance of salmonids, sculpins, and salamanders in streams. Canadian Journal of Fisheries and Aquatic Sciences 40:1173-1185.

Hawryshyn, C.W., M.G. Arnold, D.J. Chaisson, and P.C. MarTin. 1989. The ontogeny of ultraviolet photosensitivity in rainbow trout. Visual Neuroscience 2:247254.

Hawryshyn, C.W., and W.N. McFarland. 1987. Cone photoreceptor mechanisms and the detection of polarized light in fish. Journal of Comparative Physiology 160:459-465.

Henderson, M.A., and T.G. NorThCote. 1985. Visual prey detection and foraging in sympatric cutthroat trout (Salmo clarki clarki) and Dolly Varden (Salvelinus malma). Canadian Journal of Fisheries and Aquatic Sciences 42:785-790.

HoAR, W.S. 1942. Diurnal variations in feeding activity of young salmon and trout. Journal of the Fisheries Research Board of Canada 6:90-101.

1953. Control and timing of fish migration. Biological Reviews. Cambridge Philosophical Society 28: $437-452$.

JENKINS, T.M., JR. 1969. Night feeding of brown and rainbow trout in an experimental stream channel. Journal of the Fisheries Research Board of Canada 26:32753278.

Jenkins, T.M., Jr., C.R. Feldmeth, and G.V. Elliott. 1970. Feeding of rainbow trout (Salmo gairdneri) in relation to abundance of drifting invertebrates in a mountain stream. Journal of the Fisheries Research Board of Canada 27:2356-2361.
Johnson, T.B., F.B. Salisbury, and G.I. Connor. 1966. Ratio of blue to red light: a brief increase following sunset. Science 155:1663-1665.

LANDLESS, P.J. 1976. Demand-feeding behaviour of rainbow trout. Aquaculture 7:11-25.

LEwIS, S.L. 1969. Physical factors influencing fish populations in pools of a trout stream. Transactions of the American Fisheries Society 98:14-19.

Mazur, M.M., And D.A. Beauchamp. 2003. A comparison of visual prey detection among species of piscivorous salmonids: effects of light and low turbidities. Environmental Biology of Fishes 67:397-405.

McCormack, C.A., T.J. Hayden, and Y.W. Kunz. 1989. Ontogenesis of diurnal rhythms of CAMP concentrations, outer segment disc shedding and retinomotor movements in the eye of the brown trout, Salmo trutta. Brain Behavior and Evolution 34:65-72.

McFarLand, W.N., AND R.W. Munz. 1976. The visible spectrum during twilight and its implications to vision. Pages 249-270 in G.C. Evans, R. Bainbridge, and O. Rackham, editor, Light as an ecological factor, II. Blackwell Scientific Publications, Oxford, U.K.

McIntosh, A.R., T.A. Crowl, And C.R. Townsend. 1994. Size-related impacts of introduced brown trout on the distribution of native, common river galaxias. New Zealand Journal of Marine and Freshwater Research 28:135-144.

McIntosh, A.R., And C.R. Townsend. 1995. Contrasting predation risks presented by introduced brown trout and native common river galaxias in New Zealand streams. Canadian Journal of Fisheries and Aquatic Sciences 52:1821-1833.

MunZ, F.W., and W.N. MCFarLand. 1973. The significance of spectral position in the rhodopsins of tropical marine fishes. Vision Research 13:1829-1874.

Nelson, J.S., E.J. Crossman, H. Espinosa-Perez, L.T. Findley, C.R. Gilbert, R.N. LEA, AND J.D. Williams. 2004. Common and scientific names of fishes from the United States, Canada, and Mexico. American Fisheries Society, Special Publication 29, Bethesda, MD.

Newman, M.A. 1956. Social behavior and interspecific competition in two trout species. Physiological Zoology 29:64-81.

Novales-Flamarioue, I., AND C.W. HaWryshyn. 1997. Is the use of underwater polarized light by fish restricted to crepuscular time periods? Vision Research 37:975989.

OswaLD, R.L. 1978. The use of telemetry to study light synchronization with feeding and gill ventilation rates in Salmo trutta. Journal of Fish Biology 13:729-739.

Parkyn, D.C., and C.W. Hawryshyn. 2000. Spectral and ultraviolet-polarisation sensitivity in juvenile salmonids: a comparative analysis using electrophysiology. Journal of Experimental Biology 203:1173-1191.

Partridge, J.C. 1990. The colour sensitivity and vision of fishes. Pages 167-184 in P.J. Herring, A.K. Campbell, M. Whitfield, and L. Maddock, editors, Light and life in the sea. Cambridge University Press.

Richardson, J.S. 1993. Limits to productivity in streams: evidence from studies of macroinvertebrates. Pages 9-15 in R.J. Gibson and R.E. Cutting, editors, Production of juvenile Atlantic salmon, Salmo salar, in natural waters. Canadian Special Publication of Fisheries and Aquatic Sciences 118. 
Rimmer, D.M., and U. PAim. 1989. Effects of temperature, photoperiod, and season on the photobehaviour of juvenile Atlantic salmon (Salmo salar). Canadian Journal of Zoology 68:1098-1103.

Robinson, F.W., And J.C. TAsh. 1979. Feeding by Arizona trout (Salmo apache) and brown trout (Salmo trutta) at different light intensities. Environmental Biology of Fish 4:363-368.

SAS InstituTE, InC. 1997. SAS/STAT software: changes and enhancements through release 6.12. SAS Institute, Inc., Cary, NC.

Schutz, D.C., And T.G. Northcote. 1972. An experimental study of feeding behavior and interaction of coastal cutthroat trout (Salmo clarki clarki) and Dolly Varden (Salvelinus malma). Journal of the Fisheries Research Board of Canada 29:555-565.

Shuler, S.W., R.B. Nehring, And K.D. FausCh. 1994. Diel habitat selection by brown trout in the Rio Grande River, Colorado, after placement of boulder structures. North American Journal of Fisheries Management 14:99-111.

SonTAG, C. 1971. Spectral sensitivity studies on the visual system of the praying mantis, Tenodera sinensis. Journal of General Physiology 57:93-112.

SwIFT, D.R. 1962. Activity cycles in the brown trout (Salmo trutta Lin.) 1. Fish feeding naturally. Hydrobiologia 20:241-247.

1964. Activity cycles in the brown trout (Salmo trutta L.) 2. Fish artificially fed. Journal of the Fisheries Research Board of Canada 21:133-138.

TANAKA, H. 1970. On the nocturnal feeding activity of rainbow trout (Salmo gairdneri) in streams. Bulletin. Freshwater Fisheries Research Laboratory (Tokyo) 20:73-82.

Tippets, W.E., AND P.B. MoyLE. 1978. Epibenthic feeding by rainbow trout (Salmo gairdneri) in the McCloud
River, California. Journal of Animal Ecology 47:549559.

TušA, I. 1968. On the feeding biology of the brown trout (Salmo trutta m. fario L.) in the Loucka Creek. Zoologicke Listy. 17:379-395.

Wagner, H.-J. 1990. Retinal structure of fishes. Pages 109-148 in R.H. Douglas and M.B.A. Djamgoz, editors, The visual system of fish. Chapman and Hall, New York.

WetzeL, R.G. 2001. Limnology: lake and river ecosystems. 3rd edition. Academic Press, New York.

Wetzel, R.G., And G.E. Likens. 1991. Limnological analyses. 2nd edition. Springer-Verlag, New York.

Williamson, C.E. 1995. What role does UV-B radiation play in freshwater ecosystems? Limnology and Oceanography 40:386-392.

Wilzbach, M.A., K.W. Cummins, and J.D. Hall. 1986. Influence of habitat manipulations on interactions between cutthroat trout and invertebrate drift. Ecology 67:898-911.

Young, M.K., R.B. Rader, And T.A. Belish. 1997a. Influence of macroinvertebrate drift and light on the activity and movement of Colorado River cutthroat trout. Transactions. American Fisheries Society 126:428437.

Young, M.K., R.N. Schmal, T.W. Kohley, and V.G. LEONARD. 1996. Conservation status of Colorado River cutthroat trout. USDA Forest Service, General Technical Report RM-GTR-282.

Young, M.K., R.A. Wilkison, J.M. Phelps, III, And J.S. GRIFFITH. 1997b. Contrasting movement and activity of large brown trout and rainbow trout in Silver Creek, Idaho. Great Basin Naturalist 7:238-244.

Received 5 October 2006 Accepted 25 April 2007 